\title{
A EMERSIOLOGIA DO CORPO VIVO NA DANÇA CONTEMPORÂNEA
}

\author{
B. ANDRIEU ${ }^{1}$ e T. P. NÓBREGA ${ }^{2 *}$ \\ ${ }^{1}$ Universidade Paris-Descartes \\ ${ }^{2}$ Universidade Federal do Rio Grande do Norte - UFRN \\ pnobrega68@gmail.com*
}

Artigo submetido em fevereiro/2016 e aceito em abril/2016

DOI: $10.15628 /$ holos.2016.4187

\section{RESUMO}

O artigo apresenta a emersiologia como um novo contexto para a filosofia do corpo e possíveis relações com as práticas corporais, em particular a dança contemporânea. Apresentamos o campo teórico e as relações entre o corpo vivo e o corpo vivido por meio dos relatos e obras de artistas como Hélio Oiticica. A emersiologia e as artes imersivas ampliam as configurações fenomenológicas ao enfatizar o corpo em ato. A prática dançante emerge de uma ação do corpo e de suas implicações sobre o mundo e sobre nós mesmos, constituindo-se como uma experiência sensorial na qual a arte e vida se fundem.

PALAVRAS-CHAVE: corpo, sensação, filosofia, estética

\section{THE LIVE BODY EMERSIOLOGY IN CONTEMPORARY DANCE}

\begin{abstract}
The article present the emersiology as a new context for the philosophy of the body and create relationships with bodily practices, in particular contemporary dance. We present the theoretical framework and the relationships between the living body and the lived body through the stories and works of artists such as Hélio Oiticica. The
\end{abstract}

emersiology and immersive arts extend the phenomenological settings to emphasize the body in action. The dance practice emerges from a body action and its implications about the world, about ourselves establishing itself as a sensory experience in which art and life merge.

KEYWORDS: body, sensations, philosophy, aesthetics, epistemology. 


\section{A EMERSOLOGIA DO VIVO}

Se concordamos em conferir os atributos de um médium ao artista, devemos então recusar-lhe a faculdade de ser plenamente consciente, sobre o plano estético, a respeito do que ele faz ou porque ele faz - todas as suas decisões na execução artística da obra permanecem no domínio da intuição e não podem ser traduzidas em uma self-analyse, falada, escrita ou mesmo pensada (DUCHAMP, 1987, passim).

Marcel Duchamp, em 1957, ao refletir sobre o processo criativo, oferece-nos elementos ainda atuais para contextualizar nossa pesquisa sobre a improvisação imersiva na dança contemporânea e as relações entre o corpo vivo e o corpo vivido que ultrapassam o quadro fenomenológico da percepção e da intencionalidade da consciência, em particular na experiência estética e na produção artística. Em nosso ensaio, os argumentos apresentados articulam referências de vários domínios do pensamento, dialogando conceitos científicos, filosóficos e artísticos. Assim, objetivamos apresentar elementos que configuram uma filosofia do corpo e produzir uma circulação de sentidos retirados de exemplos de uma cartografia mais abrangente da visibilidade do corpo em processos de improvisação e criação coreográfica em dança contemporânea.

Com esse propósito encontramos na emersiologia um novo contexto para a filosofia, para os estudos do corpo e para uma compreensão estética da dança contemporânea capaz de ampliar a linguagem coreográfica, a carta do visível e do movimento dançante. Na primeira parte do artigo apresentamos as linhas gerais que configuram a emersiologia enquanto uma noção teórica elaborada pelo filósofo francês Bernard Andrieu e cujo aprofundamento pode ser buscado nas referências teóricas aqui indicadas. Ao estudar a história do corpo no século XX, Andrieu (1993) apresenta três modelos fundamentais para a filosofia do corpo, a saber: o modelo fenomenológico, o modelo psicanalítico e o modelo das neurociências. Compreendemos que a emersiologia se configura na interface dessas abordagens da corporeidade e das relações do corpo vivo e do corpo vivido, conscientes e inconscientes; bem como no contexto de experiências estesiológicas ${ }^{1}$.

Ao sublinhar a dispersão do corpo nessas análises, Andrieu (1993) ressalta as dificuldades da expressão linguística para expressar nossas sensações, sentimentos e experiências: "Eu não encontro palavras para dizer. Procuro uma palavra que corresponda ao que penso. Eis algumas experiências que provam a inaptidão da expressão linguística para incarnar o sentido subjetivo da impressão" (ANDRIEU, 1993, p. 273). Considerando-se esse contexto da dispersão da história do corpo e de suas ideias científicas, filosóficas ou psicanalíticas, entendemos que a emersiologia busca criar uma perspectiva de compreensão da corporeidade que reúna essas dimensões em um processo de descontinuidade entre o corpo vivo e sua experiência vivida.

\footnotetext{
${ }^{1}$ Sobre a estesiologia do corpo sugere-se a consulta das notas e resumos de cursos ministrados por Merleau-Ponty sobre a Natureza (Merleau-Ponty, 1995). Nesse conjunto de cursos, o filósofo irá mostrar a estesiologia como ciência dos sentidos, ampliando a perspectiva da ciência positivista que considera a sensação apenas no contexto da causalidade linear do estímulo-resposta. A sensação e, portanto, a estesiologia, abrange a maneira como o ser vivo, em especial o ser humano, configura o seu esquema corporal e a intercorporeidade como dimensão ontológica e existencial. Ainda sobre a estesiologia sugere-se a consulta aos estudos de Nóbrega (2015), sobre a dança e a expressão do corpo estesiológico.
} 
Ao estabelecer o princípio básico da emersiologia, Andrieu (2014) afirma existir um "atraso da consciência sobre a atividade do cérebro vivo. As neurociências in vivo demonstraram que a partir de 40 milésimos de segundo o corpo vivo poderia ativar em seu cérebro uma assinatura da presença do mundo" (Andrieu, 2014, p. 4). Para o autor, a emersiologia nasce da emersão sensível na consciência do corpo vivido, envolvendo o movimento voluntário em nosso corpo de redes de humores e imagens em nossa consciência. Nesse contexto, o corpo vivo produz sensíveis pela sua ecologização com o mundo e com os outros. Mas, em razão do tempo da transmissão nervosa de $450 \mathrm{~ms}$ até a consciência, o que se passa no corpo vivo é conhecido apenas em atraso pela consciência que configura experiência do corpo vivido. Assim, "o atraso com o qual a consciência do corpo vivido reconstitui uma narrativa torna imperceptível o que faz o corpo vivo: sem nos darmos conta o corpo vivo realiza gestos e decisões que o adaptam as modificações do ambiente" (ANDRIEU, 2014, p. 4). Esse é o princípio ontológico fundamental da emersiologia a partir do qual Bernard Andrieu constrói sua filosofia do corpo (Andrieu, 2014; 2014 a; 2015; 2015 a; 2015 b).

Segundo Andrieu (2014), essa percepção fenomenológica que o define o corpo vivido com uma imagem do corpo é qualitativamente menos intensa que o vivo do esquema corporal ${ }^{2}$, imerso no corpo das experiências sensíveis. Por sua sensibilidade, o corpo vivo é "sem sujeito", posto que o sujeito consciente não controla a atividade orgânica, nem a ativação cerebral. É a vicariância de seu cérebro quando de sua ecologização que cria redes e formas anteriores à consciência: o "esquema corporal constituído por redes neuronais simulam propriedades do corpo próprio" (BERTHOZ, 2013, p. 71). O corpo vivo nos imerge nas condições do organismo, ecologizando suas interações com o mundo a ponto de nos manter em inserção com sensações internas como a dor, o êxtase, a doença ou o envelhecimento. Nosso corpo vivo sofre, goza ou decide antes mesmo que o saibamos pelo corpo vivido, pela consciência.

Para Andrieu (2014), convém evitar aqui um vitalismo finalista que atribuiria uma intencionalidade representacional do corpo vivo. Nesse contexto, o corpo vivo age em pessoa e não como uma pessoa. O corpo vivo age sem intermediário. Na imersão, o corpo vivo invade inteiramente a sensibilidade sem que o sujeito consiga ser extraído pela reflexão: a intensidade é tão forte que faz transbordar os quadros estesiológicos habituais, ou seja, as sensações habituais. Trata-se, com efeito, de descer um estágio, de passar do vivido ao vivo, de partir do organismo vivo para repensar não somente uma classificação do que é filosoficamente pensável, mas para fundar uma filosofia que articula a relação do corpo vivo e do corpo vivido.

Essa perspectiva não se isola apenas em uma fenomenologia e uma psicologia do vivido, nem no reducionismo científico do vivo, como mostrado nos modelos teóricos fenomenológicos, psicanalíticos e das neurociências (ANDRIEU, 1993). A proposição se sustenta em uma lógica da descontinuidade para além de uma analogia, assim a emersiologia reconhece a não redutibilidade do vivo no vivido (ANDRIEU, 2014; 2015). Nesse contexto, há quatro níveis emersivos como mostrados na figura 1: vivacidade, vitalidade, viabilidade e inviabilidade (ANDRIEU, 2015). Esses níveis se comunicam em uma lógica de descontinuidade e configuram a expressividade do vivo e da própria experiência corpórea, notadamente no caso das relações entre saúde e doença, como proposto por Andrieu (2015), em Malade encore vivant [doente, ainda vivo], por exemplo, mas também no caso da expressão artística (ANDRIEU, 2015 a), com a criação de novos esquemas

\footnotetext{
${ }^{2}$ O esquema corporal segundo Merleau-Ponty (1945) refere-se não apenas a tomada de consciência das partes do corpo e sua espacialidade, mas uma maneira afetiva e intersubjetiva da relação com o outro e com o mundo. Essa acepção também é utilizada no contexto da emersiologia.
} 
corporais que desafiam os quadros estéticos já estabelecidos e que trataremos na segunda parte deste artigo ao abordarmos a dança.

\begin{tabular}{|c|}
\hline Vivacidade \\
Resiliência---o o Vivo do sujeito \\
Vitalidade \\
Vicariância--------Viável \\
Viabilidade \\
Viável ------Vegetativo \\
Inviável \\
\hline
\end{tabular}

Figura 1: Quatro níveis da emersiologia do vivo

A viabilidade é essa atividade do vivo para manter sua forma face às mutações internas. No caso da doença, por exemplo, o corpo vivo produz estados limites dificilmente suportáveis para o doente que deve remediar, a cada dia, a representação do que é viável para o seu corpo. Nesse sentido, o sujeito conhece o que não pode suportar antes mesmo que a sensação alcançada de dor ou prazer tenha sido experimentada no corpo. O corpo é limitado pela representação psíquica de prazer e de dor tornando subjetivo a normatividade do êxtase (ANDRIEU, 2015).

O limiar de tolerância encontra aqui o da resistência. Mas, por mais inviável que ele seja, o corpo vivo afirma sua vitalidade pela emersão intensa no vivido. Nesse sentido, o vivo atravessa a fronteira do vivido para renová-lo indefinidamente pelo efeito de sua ecologização. A vitalidade transborda o vivido pela informação que emerge de maneira involuntária, como no caso da dor crônica. Essa atividade vital produzida pelo vivo desperta a consciência do vivido para experiências inéditas. Uma nova organização de seu corpo vivo emerge sem que sujeito esteja em condições de compreendê-la ou representá-la na consciência. Assim, o acolhimento da vitalidade do vivo tornase um modo de conhecimento do que meu corpo, independente de representações e de técnicas corporais estabelecidas, pode realizar. Para tanto, conseguir despojar-se do esquema corporal e da imagem do corpo habituais é uma experiência necessária que se impõe (ANDRIEU, 2012; 2015).

Face a essa vitalidade, o sujeito emersivo se revolta com vivacidade contra a intrusão do vivo pela hospitalização ou medicalização, como podemos observar, por exemplo, nos relatos dos pacientes sobre as doenças. Essa resistência do vivo contribui para a resiliência do vivido, pois mesmo se o corpo é crônico ou mortal, escrever, dizer ou testemunhar torna mais suportável pelo sentido dado por essa energia advinda do desespero que invade o estilo do doente que protesta com todas as suas forças. A vivacidade é essa partilha, essa auto-organização da consciência do vivo e não apenas do vivido para reivindicar no relato um modo de subjetivação mais que uma libertação (ANDRIEU, 2012; 2015).

A emersiologia busca investigar essa atividade que se passa abaixo do limiar de consciência, em particular por meio dos relatos em primeira pessoa de experiências vividas em situações diversas tais como o orgasmo, a vertigem, a doença, a relação com o outro, a criação artística (ANDRIEU, 2013; 2014; 2014 a; 2015; 2015 a; 2015 b). A emersiologia ao considerar essa atividade do corpo vivo busca construir uma ontologia do corpo a partir de relatos autobiográficos a respeito de experiências vividas, havendo uma descontinuidade entre o que se passa ou se passou no corpo vivo-, considerando-se a atividade do cérebro abaixo do limiar de consciência- e o próprio relato do vivido. Desse modo temos que: "a carne vivida do corpo vivo se mostra aqui imediatamente nas crônicas do corpo. Ela atinge o leitor no mais profundo de seus desejos, angústias e tabus" (ANDRIEU, 2015, p. 67). 
Assim, o método emersivo busca esse vivo que se anima das sensações internas e que não pode ser inteiramente expresso nos relatos da experiência vivida. Para Andrieu (2015 b), o objeto de pesquisa não é mais um objeto à parte e separado, mas uma parte do sujeito. Além dos relatos autobiográficos, Andrieu (2015 b) também utiliza a filmagem da narrativa corporal em sua pesquisa sobre a aprendizagem do corpo e de seus gestos nas artes do circo. O pesquisador coloca em pauta de uma parte o conhecimento do corpo próprio (esquema corporal, imagem corporal, ecologia corporal, aparência, cronogênese das aprendizagens, memórias corporais) e de outra parte uma análise reflexiva do movimento através da utilização da câmara Gro Po, adicionada ao próprio corpo de um modo auto reflexivo. "Ao invés de centrar a câmara sobre a performance, nós a voltamos sobre o corpo vivo construído no curso da ação " (Andrieu, 2015 b, p. 3). O pesquisador faz uso ainda de entrevistas a partir da observação dos filmes realizados o que permite uma verbalização em relação direta como seu corpo (auto confrontação). Esse é apenas um exemplo para compreendermos o escopo da emersiologia e de sua contribuição aos estudos da corporeidade e da descontinuidade entre as sensações do corpo vivo e o relato da experiência vivida em um contexto fenomenológico.

Essa descontinuidade entre o corpo vivo e o corpo vivido, realçada pela emersiologia, também pode ser observada no caso da dança-, em especial no caso da improvisação como técnica que mobiliza o corpo para a criação de novos esquemas corporais capazes de ampliar o potencial expressivo e de criação artística. Neste ensaio consideramos a improvisação como ilustração da emersiologia do corpo vivo, apresentando essa perspectiva tal como a compreendemos na obra de alguns artistas contemporâneos como Hélio Oiticica e outros artistas inseridos no campo da dança nos quais podemos visualizar uma experiência interativa entre o corpo e a obra para produzir uma emersão de imagens, de sensações e de afetos na consciência, no sonho ou mesmo no curso de processos imersivos (BERNARD e ANDRIEU, 2014; ANDRIEU, 2014; 2014 a; ANDRIEU, 2015a; 2015 b). A arte de mergulhar no corpo exige dispositivos imersivos. O dispositivo é um lugar, uma instância, um meio, como por exemplo, um museu ou um espetáculo, no qual a eficácia performativa é suficiente para produzir um efeito inédito no corpo. Esse efeito é uma experiência imersiva pelas emoções, imagens e sensações produzidas de maneira voluntária e involuntária.

Assim, a dança contemporânea, notadamente em sua relação com a improvisação, pode ser considerada como um exemplo das artes imersivas. Concordamos com Parente (2004) ao destacar a participação do espectador na arte contemporânea, uma vez que ele não é mais um simples espectador, ele interage com a obra, havendo um encontro que ultrapassa a noção de representação condicionada ao limiar da consciência. A obra Paragonlé de Hélio Oiticica ilustra sobremaneira esse encontro entre o espectador e a obra; bem como a dissolução das margens entre ambos.

De acordo com Andrieu (2014; 2014a), nós só percebemos o movimento do corpo acima de 450 ms da consciência e ainda no curso das sensações internas. A circulação do sangue, a amplitude respiratória, a transmissão sináptica, a regulação das redes neuronais, o movimento dos órgãos e muitas outras provas in-vivo são insensíveis na atividade do corpo consciente. 0 movimento dançante conseguiria expressar esse movimento vivo? A questão é saber se chegamos a desconstruir as técnicas aprendidas para passar ao movimento do corpo vivo ele mesmo. Seria a dança nesse caso, uma espécie de transe? De fato, quando dançamos habitamos um espaço e tempo diferentes do espaço cotidiano e que nos conecta diretamente às sensações corporais (VALÉRY, 2011). Ao dançar, mobilizamos essa estesiologia do corpo que não se reduz a uma 
consciência do ato realizado. A dança ultrapassa a coreografia como escrita de movimentos do corpo em um dado espaço e tempo (NÓBREGA, 2015).

No contexto das artes imersivas, a dança libera o corpo de suas técnicas habituais para desinibi-lo por meio de dispositivos de nudez e performances de improvisação (LES CORPS COLLECTIF, 2015; BEL, 2014; HUESCA, 2015). Desnudando a pele e a técnica, a dança comunica mais diretamente com a carne do sujeito para desprendê-la dos interditos gestuais, da descontinuidade dos ritmos e da fratura dos movimentos. Um novo esquema corporal é possível a partir da improvisação. Nesta, a incerteza, o acaso, o aleatório precipita o corpo que dança na produção de gestos e de movimentos imprevisíveis. Desprender-se para se surpreender e criar gestos inéditos. A improvisação supõe um si corporal indefinido que se executa no corpo em ato, posto que essa descoberta de si modifica a imagem do corpo e encena a plasticidade do esquema corporal.

A improvisação, semelhante ao que descreve André Breton no Manifesto Surrealista ${ }^{3}$, desconstrói a motricidade voluntária pelo abandono corporal nos movimentos: perda de controle, mistura de pontos de referência, hibridação de coordenadas. Portanto, o corpo combina suas técnicas a fim de produzir uma dança mestiça com seu corpo vivo e sua ação corporal consciente, que por sua vez se expressa no traço coreográfico. O sentido do movimento apoia-se sobre o sentido do corpo, de um corpo impróprio, locatório, instável, em devir. O corpo em ato se opõe assim ao corpo em ação. O corpo em ato é o ato cerebrante ${ }^{4}$, o corpo que atravessa sua motricidade indicando-Ihe os esquemas da ação. Esse contexto nos conduz a uma teoria do corpo e não mais somente do espírito, teoria do corpo construída também por meio da dança.

\section{ENTRAR NA DANÇA...}

Após essas considerações sobre a emersiologia e as artes imersivas como um novo contexto para a filosofia do corpo, abordamos a expressão artística de Hélio Oiticica que também nos inspira na leitura e criação em dança por sua relação com a arte da performance e do happening. Inicialmente cabe contextualizar a relação entre a performance e a dança contemporânea como uma importante forma de expressão no campo da história da arte, notadamente nos movimentos do Futurismo, Surrealismo, Dada, Bahaus, Judson Dance, bem como nos trabalhos coreográficos de Anna Haplrin, Pina Bausch e Jérôme Bel (GOLDEBERG, 2012). Essas são apenas algumas referências que contextualizam do ponto de vista social e histórico essa perspectiva da arte e notadamente da dança contemporânea, o que, evidentemente, não exclui outras leituras e pontos de vista ideológicos, estéticos ou políticos.

Nota-se que Hélio Oiticica e Lygia Clark não são artistas vinculados diretamente ao domínio da dança. No entanto, conforme afirma o próprio artista, a dança, e em particular o samba, pelo grau de liberdade de movimento, inspirou-lhe em sua obra, notadamente na criação dos Parangolés. Ressalta-se ainda que a obra de ambos apresenta um conteúdo ligado ao happening e a performance que também se encontra na proposição coreográfica contemporânea como bem documentado na Exposição Danser sa vie (MACEL; LAVIGNE, 2011).

\footnotetext{
${ }^{3}$ O Surrealismo é um movimento artístico que surge nos anos 1920 em Paris, tendo por base elementos como o sonho e o inconsciente como expressão. Artistas como Salvador Dali e André Breton fazem parte desse movimento.

${ }^{4}$ Neologismo que significa o ato espontâneo que constitui a travessia da ação do cérebro no corpo.
} 
Nesse contexto, enfatiza-se o processo criativo e o uso intensivo da experimentação e da improvisação. Uma referência significativa neste cenário é o coreógrafo Steve Paxton através da técnica criada por ele, a saber, o Contact Improvisation (Contato Improvisação). Esse método consiste em realizar laboratórios de movimentos a partir do contato de dois ou mais corpos, usando princípios do momento, do peso, fluência e confiança. "Doravante, o movimento de cada corpo responde ao movimento do outro (...). Os dois corpos formam um só corpo" (GIL, 2004, p. 116). Nesse diálogo corporal, acontece a fluência dos movimentos e a criação do gesto dançante.

O método da coreografa alemã Pina Bausch também é referência e tem seu princípio básico de criação na improvisação, articulando perguntas e respostas aos bailarinos sobre suas experiências e transformando essas respostas em cenas coreográficas. Nesse processo, a coreógrafa investe em estratégias de livre associação entre as cenas, combinando a fragmentação da narrativa coreográfica com a repetição de gestos, movimentos do cotidiano, experiências vividas e relatadas pelos bailarinos.

Nesse cenário da dança contemporânea, figuras expressivas como Steve Paxton e Pina Bausch elaboraram novas cartas do visível e do movimento, alterando a percepção, o modo de ver a dança e o modo de expressão do corpo em cena que ampliam nossa reflexão sobre a corporeidade, o processo de criação e a expressão estética. No Brasil, o trabalho de Hélio Oiticica pode ser considerado uma referência da arte contemporânea. Assim, em nossa compreensão, apoiada nos autores aqui já citados, os desdobramentos estéticos da obra desse artista formulam questões para o campo da dança e da arte coreográfica ainda não inteiramente alcançados, mas já anunciados no campo artístico (MACEL; LAVIGNE, 2011).

Yes, nós temos banana! Pop-art e Tropicália são criações que impulsionaram a obra de Caetano veloso e de Hélio Oiticica, fazendo vibrar a criação no Brasil e na arte contemporânea ${ }^{5}$. A obra de Hélio Oiticica é uma referência estética do corpo estesiológico, das sensações e da expressão tal como as compreendemos. Ele viveu intensamente os seus 43 anos, sendo um dos raros casos na arte brasileira em que o artista elabora teorias, conceitua e pensa sua própria obra. Hélio Oiticica desenvolveu uma poética singular ao longo de uma trajetória fortemente influenciada pelo trabalho de Mondrian, Duchamp, Kandinsky e pela Pop-art.

A expressão de Hélio Oiticica é uma exaltação sensorial na qual se dá a passagem à obra. Suas performances, assim como as de Ligia Clark, têm como foco o corpo que se move, a experiência do movimento e as sensações que ele produz como como gesto artístico e existencial. Compreendemos que as obras desses artistas se afinam com o contexto das artes imersivas e da emersiologia, bem como com o cenário da dança contemporânea. Nessa compreensão da arte as sensações compõem a expressão do corpo, como podemos ler no relato de Lygia Clark.

A expressão corporal tem aqui uma importância essencial- pois é através dela que as células são construídas, por exemplo, abrindo os braços, criando com as pernas abertas túneis onde as pessoas podem passar. Trata-se de um abrigo poético onde o habitar é o equivalente de comunicar. Os movimentos do homem constroem esse abrigo celular habitável partindo de um nó que se mistura aos outros. Uma folha de plástico estendida no chão não é nada ainda. É o homem que a

\footnotetext{
${ }^{5}$ Para outras informações sobre a biografia e a obra de Hélio Oiticica visite o site http://www.heliooiticica.org.br/home/home.php
} 
penetrando, a cria e a transforma, pois ele desenvolve, no interior, comunicações táteis (CLARK, 2005, p. 13).

As proposições de Lygia Clark e as de seu parceiro Hélio Oiticica se realizam a cada vez que acontece a relação poética dos seus receptores com as coisas, não mais como objetiva ou objetiváveis, as quais seriam portadoras de um poder mágico consistindo em mobilizar o sopro vital do seu receptor, mas como potência de invenção. Não se trata mais de uma relação de contemplação entre o sujeito e o objeto, o espectador e a obra, mas a imersão no espaço no qual o corpo vivo e sua sensibilidade ocupam todo o plano da ação. A intensidade é tão forte que transborda os quadros estesiológicos ${ }^{6}$ habituais, despertando sensações novas que fazem emergir novos esquemas corporais que podem se tornar conscientes por exemplo na criação artística ou nos relatos das experiências do corpo vivido. A questão importante aqui é justamente essa emergência de novos esquemas corporais, novos estados estesiológicos que nos descondicionam dos padrões habituais, metamorfoseando nossa corporeidade e nossa percepção de nós mesmos, das coisas, dos mundos.

Há aqui uma aproximação entre a dança e a performance que queremos realçar e que foi apontada no dossiê pedagógico da exposição Danser sa vie, realizada no Centro Georges Pompidou, em Paris, no ano de 2012. Essa aproximação do caráter efêmero da dança inspirou muitos artistas, sendo esse o foco de toda a exposição que reuniu artistas plásticos, músicos, coreógrafos, diretores de teatro, entre outros, sobretudo a partir da segunda metade do século XX. Artistas como Isadora Duncan e Mary Wigman, por exemplo, buscavam uma dança mais próxima das sensações do corpo vivo e do contato com a natureza para além dos códigos sociais construídos no campo das artes e da dança em particular, como documentado na referida exposição (MACEL; LAVIGNE, 2011).

Destacamos na exposição Danser sa vie artistas como Merce Cunnigham, Robert Morris, Anne Halprin, Jérôme Bel, entre outros. Uma das expressões mostradas nesta exposição foi a coreografia The Show Must Go On, de Jérôme Bel, criada em 2001. A coreografia apresenta vinte dançarinos, profissionais ou não, que se movimentam escutando seus heads-phones. As músicas foram escolhidas pelo coreógrafo, representando um repertório de sucessos (tubes), incluindo a Macarena. Os dançarinos vestidos com suas roupas cotidianas se movimentam e cantam durante alguns minutos. Essa coreografia contém um questionamento sobre o que é a dança e mesmo sobre o que é a coreografia e a obra de arte em dança. Tal questionamento nos remete a Marcel Duchamp, criador do conceito de ready made, segundo o qual a arte é criada a partir do transporte de um elemento da vida cotidiana, a princípio não reconhecido como artístico, para o campo das artes, como podemos perceber na emblemática obra La Fountain, de 1917 (MACEL; LAVIGNE, 2011).

Essa atitude estética também influenciou a busca por novas visibilidades cênicas na dança contemporânea. Nota-se aqui uma dissolução das fronteiras entre a arte e a vida, uma dissolução das fisionomias, dos gestos e dos modelos figurativos elaborados pela tradição coreográfica clássica. Na dança contemporânea há uma certa economia do corpo, uma vez que se trata de outro registro estético, outro registro de movimento e de sua visibilidade. Assim, por exemplo, Jérôme Bel busca habitar diferentemente o cenário da dança baseado em representações coreográficas

\footnotetext{
${ }^{6}$ A estesiologia expressa uma filosofia do corpo como carne, que é o oposto de representações conscientes, mas que é o sentir mesmo (MERLEAU-PONTY, 1995).
} 
através de uma economia do corpo e dos movimentos. Ele busca encenar as experiências vividas, dando voz aos intérpretes como no caso da peça Véronique Doisneau em que a bailarina da Ópera de Paris narra sua trajetória artística, sua fragilidade física, as peças que mais gostava de dançar, o desejo de fazer papéis masculinos e o sonho de dançar Giselle, entre outros acontecimentos que marcaram sua vida como bailarina.

Eu passei da representação de um corpo objeto a um corpo sujeito. Eu analisei inicialmente a alienação cultural, social e econômica sobre o corpo, depois eu coloquei em cena o dançarino, objeto da dança, de tal maneira que ele (Cédric Andrieux) e ela (Véronique Doisneau) acederam a posição de sujeito. É a linguagem que permitiu essa operação (BEL, 2014, p. 4).

Destaca-se que os gestos do cotidiano são tomados de empréstimo da experiência da vida ordinária e passam a integrar o vocabulário coreográfico no trabalho de muitos artistas que compõem o cenário da dança contemporânea. Comer uma maça, vestir-se e muitos outros gestos inscrevem-se em uma teatralidade que vão despertar no espectador essa sensibilidade e produzir essas experiências imersivas do corpo vivo, do corpo em ato, cuja expressividade pode ser transformada pela criação artística. Podemos documentar essa perspectiva no trabalho da coreografa alemã Pina Bausch, a saber:

Sentada no meio dos bailarinos ela faz calmamente as suas perguntas. Ninguém é obrigado a responder. Quem sente vontade de o fazer, levantase, coloca-se diante dela e responde como entende: não existe qualquer limitação ou indicação sobre a maneira de responder. A resposta pode ser verbal ou gestual, pode reduzir-se a uma imagem muito simples ou transformar-se numa sequência de dança improvisada; pode exprimir-se tanto por meio de uma só palavra como de uma longa narrativa. Seja qual for a resposta o bailarino que a formulou deverá escrevê-la para não a esquecer e para poder reproduzi-la durante a fase seguinte - a montagem propriamente dita do espetáculo-, quando Pina Bausch o pedir. Pelo seu lado, ela registra as respostas de toda a gente, sem excluir nenhuma delas. Só mais tarde, terá lugar a escolha do material. Duas semanas depois, a encenação, na colagem que constitui o resultado final, montará uma seleção que recorre ao material recolhido durante, pelo menos, dois meses de ensaio (GIL, 2004, p. 172,173).

Nessa citação temos um resumo do processo de composição coreográfica de Pina Bausch, destacando-se as perguntas e respostas, os registros escritos das respostas, a seleção do material que será utilizado na montagem. Na montagem, as cenas criadas a partir das respostas dos bailarinos são associadas por meio da colagem, recurso muito usado pelos artistas surrealistas, criando os temas ou frases de movimento que irão compor as cenas por meio das repetições. Perguntas, respostas, colagem que originam as frases e temas de movimento, as repetições são, portanto, a base de seu método de composição coreográfica. Esse método reúne outros elementos essenciais como a fala, os gestos do cotidiano, a música, o cenário, os adereços.

Nas peças coreográficas de Pina Bausch a palavra se faz presente nas canções, em poemas, em frases repetidas pelos bailarinos. A palavra e o gesto estão presentes em todas as peças e produzem uma nova relação entre o corpo e a dança para além do virtuosismo da técnica. Ela toca profundamente nossa emoção com gestos simples, ela muda o modo de ver a dança. Com Pina 
podemos dançar. Ela nos oferece um método de criação em dança que permite que todos possam dançar. Nesse contexto, a dança é uma forma de expressão da existência humana, uma forma de expressar a vida. Com a palavra Pina:

\begin{abstract}
A dança deve ter outra razão além de simples técnica e perícia. A técnica é importante, mas é só um fundamento. Certas coisas se podem dizer com palavras, e outras, com movimentos. Há instantes, porém, em que perdemos totalmente a fala, em que ficamos totalmente pasmos e perplexos, sem saber para onde ir. É aí que tem início a dança, e por razões inteiramente outras, não por razões de vaidade. Não para mostrar que os dançarinos são capazes de algo de que um espectador não é. Há de se encontrar uma linguagem com palavras, com imagens, movimentos, estados de ânimo que faça pressentir algo que está sempre presente. Esse é um saber bem preciso. Nossos sentimentos, todos eles, são muito precisos. Mas é um processo muito, muito difícil torná-los visíveis. Sempre tenho a sensação de que é algo com que se deve lidar com muito cuidado. Se eles forem nomeados muito rápido com palavras, desaparecem ou se tornam banais. Mas, mesmo assim, é um saber bem preciso o que todos temos, e a dança, a música etc. são uma linguagem bem exata, com que se pode fazer pressentir esse saber. Não se trata de arte, tampouco de mero talento. Trata-se da vida e, portanto, de encontrar uma linguagem para a vida. $E$, como sempre, trata-se do que ainda não é arte, mas daquilo que talvez possa se tornar arte (BAUSCH, 2000, p. 1).
\end{abstract}

Na dança contemporânea muitos artistas buscam fazer essa economia do corpo, muitas vezes recorrendo ao teatro, à linguagem falada e a outros meios técnicos e tecnológicos, construindo cenários híbridos para a cena coreográfica nos quais as narrativas das experiências cotidianas vividas pelos artistas ganham destaque. Parece haver um desejo de comunicar aquilo que se passa com as emoções dos dançarinos e suas histórias para além dos códigos coreográficos já estabelecidos, mesmo àqueles mais bem-sucedidos como vemos em Pina Bausch. Nesse cenário, entendemos que improvisação imersiva se apresenta como possibilidade para o processo criativo e sua expressividade.

Além dos artistas europeus aqui mencionados, encontramos essa improvisação imersiva na obra do artista brasileiro Hélio Oiticica. Artista plástico e performático para quem a arte é tida como sensação, Hélio Oiticica enfatiza a relação do corpo com a obra, o que ele denomina de incorporação. Em sua obra, a pintura sai do quadro e vai para o espaço, a arte é compreendida como experimentação no mundo. Os Parangolés e suas questões corporais, cromática e rítmicas não cabiam no espaço institucionalizado do museu segundo as normas vigentes (FAVARETTO,1992; PEQUENO, 2013). A partir desse momento a relação com o espaço, com a dança, em particular com a improvisação do samba, irá se tornar cada vez mais intensa em sua arte como forma de catalisar energias dispersas, conectando-se diretamente com o espectador através das obras em movimento.

A obra é um estado de invenção. Experimentando os Parangolés criamos imagens moveis e rápidas, assim a obra se faz com a deformação e transformação dos movimentos e das sensações que se produzem em nosso corpo. $O$ espectador participa da obra com o corpo inteiro. $O$ uso do espaço, a relação com a sensibilidade, a vida. O Parangolé não é para ver, é para dançar. O público penetra na obra, a ideia é que as pessoas transformem a vida em obra de arte (OITICICA, 2011). As obras de Hélio Oiticica são espaços de experimentação do corpo. A ideia de coletividade e de 
êxtase estão presentes em seu trabalho. Os Parangolés possibilitam a metamorfose de transformação do corpo em obra de arte.

Os Parangolés são convites para se colocar em cena, dançar e refletir sobre a vida, a sociedade, a estética, por meio da relação com o material: as capas com suas cores e palavras dirigidas ao corpo como na capa "Eu incarno a revolta", criada em 1967. O desenvolvimento da experiência dos Parangolés seguiu uma trajetória na qual podemos identificar as capas coloridas do início dos anos 1960 e a concentração sobre o corpo em movimento. As capas sociopolíticas a partir de meados dos anos 1960 nas quais aparecem o recurso às palavras (como na capa: " eu incarno a revolta"); as capas criadas em New York nos anos 1970 mais abstratas, transparentes e que buscam expressar o vazio segundo o artista (OITICICA, 2011).

"Devo precisar que meu interesse pela dança, pelo ritmo, particularmente o samba, vem de uma necessidade vital de "desintelectualização", uma necessidade de me exprimir livremente (OITICICA, 2011a, p. 171). Ele retoma o sentido dionisíaco que Nietzsche atribuiu a dança, no sentido de ato expressivo direto no qual predomina a improvisação ao invés de uma coreografia. Esse sentido de imanência do corpo por meio da dança permite a incorporação e a metamorfose do corpo como obra de arte. Nos Parangolés podemos observar a dança orgânica, uma dança do corpo vivo, ou seja, uma dança que se liberta da forma coreográfica, dos gestos codificados e nos coloca em estado de invenção. Não se trata apenas de contemplar o objeto, a coreografia, mas de entrar na dança, fazer corpo com o espaço através do movimento, do ritmo, da respiração, das sensações que percorrem todo o corpo.

Artista inquieto, Oiticica (2011) afirma que a arte deve ser feita para ser sentida, para fazer vibrar o corpo e nos liberar de nossos condicionamentos morais, sociais, estéticos. De acordo com Nóbrega (2015), trata-se de uma arte inscrita na vida, uma arte que sai do espaço do quadro, da cena tradicional, da coreografia para ganhar outros espaços e para criar novos esquemas corporais. Trata-se de uma ecoreografia, posto que ultrapassa a normatividade coreográfica para interagir mais amplamente com o espaço, com o tempo, com os objetos e com o corpo do outro. A obra Supra Sensorial, na qual somos convidados a tocar, sentir a cor e a colorir-se com ela, sublinha essa sensorialidade, produzindo novos esquemas corporais e uma nova maneira de interagir com a arte. Já os Parangolés liberam a dança do corpo por meio dos contatos com os panos, as capas coloridas e a intensidade rítmica dos movimentos. Tal aspecto ilustra o propósito da emersiologia e sua ênfase nas sensações do corpo vivo, não inteiramente representados pela consciência; bem como dos aspectos da vitalidade, vivacidade e viabilidade do corpo e de seus processos de criação de esquemas corporais os quais podem ser visualizados em muitas obras artísticas em geral e coreográficas, em particular, como buscamos apresentar nesse ensaio (ANDRIEU, 2014; ANDRIEU, 2015 b).

A experiência artística de Hélio Oiticica nos inspira em nossa relação com a dança. Vestirse de dança, liberar o movimento, ocupar o espaço, incorporar-se ao ambiente. A arte sai do espaço convencional e nesse movimento o corpo torna-se obra de arte, tal como ocorre, por exemplo, na obra Tropicália, na qual penetramos esses labirintos, em um auto-teatro, uma maneira poética de interpretar o espaço que nos convida a nos metamorfosearmos em uma dança que não é aprisionada pela coreografia. Os labirintos, os penetráveis, os Parangolés e outras performances artísticas de Hélio Oiticica descondicionam nossa postura, exigem novos movimentos, produzem um rastro de alegria na arte, uma nova poética na dança contemporânea ainda não inteiramente realizada (NÓBREGA, 2015). 


\section{CONSIDERAÇÕES FINAIS}

Compreendemos que a emersiologia busca apreender a descontinuidade entre o corpo vivo e o corpo vivido, reunindo princípios advindos da fenomenologia, da psicanálise, das neurociências, das artes imersivas. Assim, atenta aos relatos autobiográficos, aos relatos em primeira pessoa das narrativas corporais da experiência vivida, a emersiologia cria uma perspectiva de pesquisa para os estudos da corporeidade, apresentando ainda um vocabulário que tenta dar conta da descontinuidade entre o corpo vivo e o corpo vivido, as sensações e a reflexão, a consciência e o que permanece no inconsciente.

Neste artigo apresentamos aproximações entre a emersiologia como um novo contexto para filosofia do corpo, para a criação artística, as experiências do corpo e das práticas corporais, em particular no que se refere à improvisação e à dança contemporânea, no sentido de ampliação do debate e dos referenciais teóricos e metodológicos relacionados aos estudos da corporeidade e do conhecimento estético em diversos domínios. Buscamos aprofundar a imersão na corporeidade e na dança, ampliando os quadros estesiológicos e estéticos da coreografia por meio da emersiologia, ou seja, aquilo que faz vibrar em nosso corpo vivo as sensações. Desse modo, a despossesão e a perda de controle do corpo contribuem para uma liberação da vontade e da capacidade de criação por meio da improvisação.

Avivando-se pela dimensionalidade do corpo e seu movimento interno, o corpo dançante aprofunda-se: por um lado, tocando sua carne zonas sensoriais inéditas pela ativação provocada pela técnica emersiva e, por outro lado, realizando gestos provindos do interior, mas atravessando a expressão em um ato corpóreo original. Entrando na dança o corpo vivo não tem a intenção consciente de se exprimir. Ele atravessa a consciência no gesto, na postura e no ritmo sem significação imediata.

A improvisação do vivo difere aqui de uma liberação das normas corporais, pois a espontaneidade da atividade que ocorre abaixo do limiar de consciência vem preencher o conteúdo da consciência do dançarino, orientando-o conforme sua intensidade e direção. Mas, a desorientação produzida pela resistência consciente do dançarino em relação ao que seu corpo vivo improvisa pode constituir um obstáculo a sua criatividade. Por outro lado, o transe, como o orgasmo ou a vertigem pode ser uma solução orgânica produzida pelo vivo para tornar suportável a perda de controle pelo dançarino e seu abandono à vida (TESSON, 2014).

Consentir abandonar-se para deixar emergir o vivo de seu corpo através da consciência não é nem um retorno ao instinto, nem uma regressão arcaica. Não se trata aqui de progresso, mas de aprofundamento. A improvisação cria um túnel de comunicação entre o vivo e o vivido, criando movimentos assimétricos e modos de exploração voluntária ou involuntária em função do grau de improvisação. Sem ser detido pela consciência, o sujeito dançante, em seu corpo vivo, pode encontrar inspiração para sua arte, como percebemos na criação de Hélio Oiticica. Assim, não é mais o eu consciente que controla a improvisação, mas o corpo vivo que é capaz de atualizar o gesto dançante, sendo capaz de acolher o que surge desse eu que se faz conhecer como uma outra parte de mim mesmo. Assim, a técnica corporal é somente um meio para o que ainda não é corpo em mim tornar-se.

No contexto das artes emersivas, a improvisação altera o quadro tradicional da coreografia como escrita da dança em termos de controle do movimento no espaço e no tempo ou de uma 
gestualidade circunscrita a domínios estéticos já estabelecidos para compor novos espaços de sensibilidade e de movimento que possibilitam a imersão no corpo e o despertar de sensações profundas da corporeidade. Nesse contexto, o movimento e o repertório gestual criam novas possibilidades de imersão, de criação artística e de experiência existencial.

\section{REFERÊNCIAS BIBLIOGRÁFICAS}

1. ANDRIEU, B. Le corps dispersé : une histoire du corps au xx e siècle. Paris : L'Harmattan, 1993.

2. ANDRIEU, B. L'autosanté: vers une médecine réflexive. Paris: Armand Collin, 2012.

3. ANDRIEU, B. La peur de l'orgasme. Strasbourg: Le murmure, 2013.

4. ANDRIEU, B. A emersão do corpo vivo através da consciência: uma ecologização do corpo. Revista Holos, ano 30, v.5, Natal, IFRN, 2014 (p.2-11).

5. ANDRIEU, B. Donner le vertige: les arts immersifs. Montreal: Liber, 2014a.

6. ANDRIEU, B. Malade, encore vivant. Strasbourg : Le murmure, 2015.

7. ANDRIEU, B. No corpo de minha mãe: método emersivo. Dans le corps de ma mère : méthode émersive. Natal : Editora do IFRN, 2015 a.

8. ANDRIEU, B. Apprendre de son corps et de ses gestes: um méthode réflexive au centre National des Arts du cirque. Paris : CNAC, 2015b .

9. BANNES, Sally. Terpsicore en baskets: post modern dance. Traduction Denise Luccuioni. Panti: CND; Chiron, 2002.

10. BAUSCH, P. Entrevista. Folha de São Paulo, 27 de agosto de 2000.Disponível no endereço eletrônico: http://www1.folha.uol.com.br/fsp/mais/fs2708200008.htm lacessado em 21/11/2014).

11. BEL, J. Dossier de presse Jérôme Bel. Festival d'Automne à Paris, 2014 (p.1-7). Disponível no endereço eletrônico http://www.festival-automne.com/edition-2014/jerom-bel-jerom-bel (acessado em 21/11/2014).

12. BERNARD, A. ; ANDRIEU, B. (Eds). Manifeste des arts immersifs. Nancy : Presses Universitares de Nancy ; Éditions Unversitaires de Lorraine, 2014.

13. BERTHOZ, A. La Vicariance. Paris: Odile Jacob, 2013

14. CLARK, L. De l'œuvre à l'événement. Nous sommes le moule. À vous de donner le souffle. Nantes : Musée des beaux-arts, 2005.

15. DUCHAMP, M. Le processus créatif. Paris: L'Échoppe, 1987.

16. FAVARETTO, C. A invenção de Hélio Oiticica. São Paulo: EDUSP, 1992.

17. GIL, J. Movimento total: o corpo e a dança. São Paulo: lluminuras, 2004.

18. GOLDBERG, R. La performance du futurisme à nos jours. Paris: Thames \& Hudson, 2012.

19. HUESCA, Roland. La danse des orifices : étude sur la nudité. Paris : Jean-Michel Place, 2015.

20. MACEL, C.; LAVIGNE, E. (Eds). Danser sa vie : écrits sur la danse. Paris : Centre Georges Pompidou, 2011.

21. MERLEAU-PONTY, M. Phénoménologie de la perception. Paris : Gallimard, 1945. 
22. MERLEAU-PONTY, M. La Nature: notes cours au Collège de France. Établi par Dominique Séglard. Paris: Seuil, 1995.

23. NÓBREGA, T.P. Sentir a dança ou quando o corpo se põe a dançar. Natal: Editora do IFRN, 2015.

24. OITICICA, H. O museu é o mundo. Rio de Janeiro: Azougue Editorial, 2011.

25. OITICICA, H. La danse dans mon experience. IN MACEL, C.; LAVIGNE, E. (Eds). Danser sa vie : écrits sur la danse. Paris : Centre Georges Pompidou, 2011 a.

26. PARENTE, A. Entrevista. Revista Psicologia e Sociedade, vol. 16, n.2, Porto Alegre, 2004.

27. PEQUENO, F. Lygia Pape e Hélio Oiticica: conversações e friç̧ões poéticas. Rio de Janeiro: Apicuri, 2013.

28. TESSON, S. S'abandonner à vivre. Paris: Gallimard, 2014

29. VALÉRY, P. L'âme et la danse. IN MACEL, C.; LAVIGNE, E. (Eds.). Danser sa vie : écrits sur la danse. Paris: Centre Georges Pompidou, 2011. 